\title{
APLIKASI COMPUTER AIDED INSTRUCTION (CAI) DALAM PEMBELAJARAN MATEMATIKA BANGUN RUANG
}

\author{
Samsudin \\ Program Studi Sistem Informasi \\ Universitas Islam Negeri Sumatera Utara Medan \\ mr.samsudin@gmail.com
}

\begin{abstract}
ABSTRAK
Pembelajaran merupakan suatu proses pengembangan diri seseorang dalam upaya memperoleh ilmu pengetahuan, keterampilan dan nilai-nilai positif dengan memanfaatkan berbagai sumber ilmu untuk belajar. Untuk mempermudah pembelajaran sehingga memperoleh hasil yang lebih maksimal, maka kita membutuhkan suatu sistem pembelajaran yang baik. Dengan sistem pembelajaran berbantuan komputer atau sering dikenal materi dari pendidik ke para peserta didiknya. Dengan adanya sistem pembelajaran berbantuan komputer maka dibuatlah sebuah sistem pembelajaran untuk menghitung rumus matematika bangun ruang dengan istilah Computer Aided Instruction (CAI), maka sistem pembelajaran ini berfungsi untuk mempermudah proses penyampaian. Dengan adanya sistem pembelajaran ini diharapkan proses pembelajaran menjadi lebih efektif dan menarik. Sehingga nantinya sistem pembelajaran untuk menghitung rumus matematika bangun ruang ini sangat dibutuhkan sebagai sarana penunjang lancarnya proses pembelajaran.
\end{abstract}

Kata kunci: CAI, Sistem Pembelajaran, Bangun Ruang

\begin{abstract}
Learning is a process of self-development in an effort to gain knowledge, skills and positive values by utilizing various sources of science to learn. To facilitate learning so as to obtain maximum results, then we need a good learning system. With computer-aided learning system or often known as Computer Aided Instruction (CAI), then this learning system serves to facilitate the process of delivering materials from educators to the students. With the computer-assisted learning system then made a learning system to calculate the mathematical Formula wake up space. With this learning system is expected to be more effective and interesting learning process. So that later the learning system to calculate the mathematical Formula to build this space is needed as a means of supporting the smoothness of the learning process.
\end{abstract}

Keywords: CAI, Learning System, Geometry.

DOI: 10.15408/jti.v10i2.6995 


\section{PENDAHULUAN}

Seiring dengan semakin majunya Teknologi Komunikasi dan Informasi (Information and Communication Technology) telah merubah model dan pola pembelajaran pada dunia pendidikan saat ini. Pembelajaran berbantuan komputer (Computer Aided Instruction) yang biasa disingkat dengan CAI merupakan suatu sistem pembelajaran dan pengajaran yang menggunakan perangkat komputer sebagai alat bantu dalam proses belajar mengajar. CAI adalah pengembangan dari teknologi informasi terpadu yang saling mendukung seperti animasi, pencitraan, audio, video dan komunikasi (interaktif) yang dikemas berbasis multimedia.

Proses pembelajaran berbasis komputer dapat dilakukan dengan berbagai program aplikasi (software), seperti Microsoft PowerPoint, Adobe Flash, Adobe Premier, Macromedia Dream Weaver, Microsoft Front Page, PHP, Java Script dan sebagainya. Selain memerlukan fitur program aplikasi komputer, proses produksi pembelajaran juga memerlukan berbagai peralatan (hardware). Seperti: Camera Foto, Camera Video, Scanner, CD/DVD Writer, dan sebagainya. Pemilihan program dan peralatan tersebut didasarkan pada tingkat kebutuhan dan keahlian pengembang program.

Secara umum didalam kehidupan sehari-hari dapat dilihat bahwa manusia lebih mudah menyerap pelajaran yang disajikan dengan bantuan komputer berbasis multimedia. Hal ini dikarenakan penyajian materi edukasi yang dapat menggunakan berbagai media seperti teks, gambar, animasi, audio dan video.

Mencermati hal tersebut ini, untuk mempermudah dalam proses pembelajaran maka penulis tertarik untuk membuat suatu sistem pembelajaran yang dapat membantu proses penyampaian materi secara interaktif. Dimana seorang pengajar tidak harus menyampaikan materi kuliah dengan berdiri sambil menerangkan materi didepan kelas secara langsung, tetapi dapat melakukan sistem pembelajaran tanpa harus bertatap muka dan siswa juga dapat mengulang-ulang materinya.

Minat belajar siswa khususnya mata pelajaran matematika sangatlah kurang termasuk materi tentang bangun ruang (Geometri). Hal ini disebabkan oleh karena siswa sering kali merasa jenuh saat mempelajari matematika termasuk materi tentang sistem

Samsudin: Aplikasi Computer... bangun ruang (Geometri). Untuk menumbuhkan minat siswa dalam mempelajarinya, maka dibutuhkan adanya sistem pembelajaran matematika untuk operasi hitung bangun ruang.

\section{TINJAUAN PUSTAKA}

\subsection{Pembelajaran Berbantuan Komputer (PBK)}

Pembelajaran Berbantuan Komputer (PBK) atau sering juga dikenal dengan sebutan Computer Assisted Instruction (CAI) adalah cara atau metode pembelajaran yang menggunakan aplikasi komputer sebagai media utamanya, yang bisa merupakan suatu program aplikasi interaktif yang dapat digunakan sebagai media penyampaian informasi maupun sebagai media evaluasi dalam proses pembelajaran. Banyak istilah asing yang menafsirkan diri sebagai PBK antara lain Computer Assisted Instruction (CAI), Computer Based Instruction (CBI), Computer Assisted Learning (CAL), Computer Managed Instruction (CMI), dan Computer Based Education (CBE) [1]. Istilah CAI umumnya menunjuk pada semua software pendidikan yang diakses melalui komputer dimana siswa mendapatkan informasi maupun latihan dan soal-soal untuk mencapai tujuan pengajaran tertentu dalam sistem komputer. Materi pelajaran dapat disajikan program CAI melalui berbagai metode seperti: tutorial, drill and practice, simulasi, games, problem-solving, discovery dan inquiry[6].

\subsubsection{Komponen dan Struktur PBK}

PBK memiliki komponen-komponen antara lain:

1. Hardware, yaitu komputer dan piranti pendukungnya

2. Software, yaitu dapat berupa sistem operasi, aplikasi, atau modul program komputer untuk merepresentasikan materi perangkat ajar

3. Brainware, yaitu pembuat sistem, pengajar, atau siswa.

Sedangkan struktur program yang dimiliki komputer antara lain:

1. Desain bentuk (aplikasi perangkat lunak)

2. Isi (pesan pembelajaran) 
3. Pendukung (perangkat lunak yang dibutuhkan dalam pengoperasian program, teks, audio, video, grafis, dan sebagainya).

Keseluruhan komponen dan struktur di atas terintegrasi dalam sebuah program dengan memperhatikan kemudahan pengoperasian, interaktivitas, kemenarikan, dan dukungan perangkat evaluasi untuk mengukur tingkat pemahaman siswa.

\subsubsection{Kategori PBK}

Secara garis besar PBK dikategorikan menjadi dua, yaitu:

\section{Computer-Based Training (CBT)}

CBT merupakan proses pendidikan berbasiskan komputer dengan memanfaatkan media CDROM dan disk-based sebagai media pendidikan[7]. Dengan media ini proses pedidikan melalui classroom tetap dapat terlaksana sehingga interaksi dalam proses pendidikan dapat terus berlangsung, yang dibantu oleh kemandirian peserta didik dalam memanfaatkan CBT.

\section{Web-Based Training (WBT)}

WBT sering diidentikkan dengan $e$ learning, dalam metode ini selain menggunakan komputer sebagai sarana pendidikan, juga memanfaatkan jaringan Internet sehingga seorang yang akan belajar bisa mengakses materi pelajarannya dimanapun dan kapanpun selagi terhubung dengan jaringan Internet [12].

\subsubsection{Karakteristik PBK}

Menurut [3], bahwa karakteristik PBK antara lain:

1. Tersedianya fasilitas komputer untuk kegiatan belajar mahasiswa

2. Program CAI dikembangkan berdasarkan kompetensi yang ingin dicapai

3. Strategi belajar dapat ditentukan dengan tutorial, drill and practice, problem solving atau simulation

4. Relevan dengan ragam karakteristik mahasiswa

5. Mengoptimalkan interaksi belajar mahasiswa dengan materi ajar

6. Memiliki potensi untuk mengatur kegiatan belajar sesuai dengan kebutuhan mahasiswa

7. Efektif untuk mempertahankan minat belajar mahasiswa
8. Memberikan pendekatan yang positif terhadap mahasiswa

9. Memberikan variasi umpan balik dan dilakukan secepat mungkin

10. Relevan digunakan untuk berbagai lingkungan belajar, dimana mahasiswa satu dan lainnya melakukan kegiatan belajar yang berbeda

11. Mampu menilai kemampuan mahasiswa secara komprehensif dan mendokumentasikan penilaian dengan baik

12. Rancangan evaluasi sesuai dengan kompetensi

13. Mampu menggunakan sumber belajar berbasis komputer secara luas.

\subsubsection{Model PBK}

PBK secara umum dibedakan menjadi empat kategori:

1. Tutorial (Penjelasan)

Jenis PBK ini digunakan untuk menyampaikan suatu materi pengajaran. Tutorial bertujuan untuk menyampaikan atau menjelaskan materi tertentu, dimana komputer menyampaikan materi, sesuai dengan bahan yang akan diajarkan. Dalam menyajikan materi, tutorial dapat dibedakan menjadi tutorial linier dan tutorial bercabang [5]. Tutorial linier menyajikan suatu topic ke topik berikutnya sesuai urutan yang telah ditetapkan oleh pemrogram, sehingga siswa tidak dapat memilih materi pembelajaran sesuai keinginan dan kemampuannya.

Sedangkan pada tutorial bercabang, perbedaaan individu diperhatikan dengan memberikan kebebasan pada siswa untuk mempelajari materi sesuai keinginan dan kemampuannya. Penyajian materi dan topik pada tutorial bercabang menyesuaikan dengan pilihan dan kemampuan siswa. Dalam hal ini, tutorial becabang memiliki kelebihan dibanding tutorial linier, karena hal-hal sebagai berikut:

a. Siswa dapat menentukan materi yang akan dipelajari

b. Pembelajaran lebih menarik, kreatif, dan fleksibel

c. Pembelajaran lebih efektif.

Dalam beberapa hal pula, tutorial diperlukan agar membantu siswa dalam mengatasi masalah belajarnya. Biasanya dengan bantuan navigasi materi yang diajarkan, tutorial akan memudahkan siswa mempelajari bagian-bagian materi tertentu. 
2. Drill and Practice (Latihan dan Praktik)

Jenis ini digunakan untuk menguji tingkat pengetahuan siswa dan mempraktekkan pengetahuan mereka, sehingga pembuatannya disesuaikan dengan tingkat kemampuan masing-masing siswa. Dalam hal ini, siswa bertugas menjawab soal setelah selesai menjawab seluruh soal, komputer memberikan feedback, atau juga memberi feedback setelah menjawab satu soal sebelum beralih ke soal berikutnya.

Latihan dan praktik juga dapat diterapkan pada siswa yang sudah mempelajari konsep (kemampuan dasar) dengan tujuan untuk memantapkan konsep yang telah dipelajari, diamana siswa sudah siap mengingat kembali atau mengaplikasikan pengetahuan yang telah dimiliki.

3. Simulation (Simulasi)

Simulasi digunakan untuk memperagakan sesuatu (keterampilan) sehingga siswa merasa seperti berada dalam keadaan yang sebenarnya. Simulasi banyak digunakan pada pembelajaran materi yang membahayakan, sulit, atau memerlukan biaya tinggi, misalnya untuk melatih pilot pesawat terbang atau pesawat tempur. Pada perangkat ajar simulasi, siswa dihadapkan pada situasi yang mirip dengan kehidupan nyata. Intinya, dunia nyata dipresentasikan dalam bentuk model dan kemudian dengan teknik simulasi siswa dapat mempelajari kelakuan sistem.

\section{Discovery (Penemuan)}

Dalam model ini siswa diminta untuk melakukan percobaan yang bersifat trial and error dalam memecahkan suatu permasalahan. Sama halnya dengan interaksi tutorial, bentuk interaksi penemuan berisi banyak alternatif solusi untuk memecahkan suatu permasalahan [11].

Dalam program yang berbentuk penemuan, siswa dapat mencari informasi dan membuat kesimpulan dari sejumlah informasi yang telah dipelajari. Dari proses belajar yang dilakukannya, siswa dapat menemukan konsep dan pengetahuan baru yang belum pernah dipelajari sebelumya.

5. Problem Solving (Pemecahan Masalah)

Menyajikan masalah-masalah untuk siswa, agar diselesaikan berdasarkan kemampuan yang mereka peroleh.

6. Games (Permainan)

Samsudin: Aplikasi Computer...
Berdasarkan tujuan belajarnya jenis permainan dibagi menjadi dua tipe, yaitu sebagai berikut:

a. Permainan Intrinsik (Intrinsic Games) Mempelajari aturan permainan dan keahlian dalam suatu permainan (games).

b. Permainan Ekstrinsik (Extrinsic Games) Permainan hanya sebagai perangkat tambahan sebagai fasilitas belajar dan membangkitkan motivasi siswa.

Pada dasarnya, model PBK ini tepat diterapkan pada siswa yang senang bermain. Bahkan, jika di desain dengan baik sebagai sarana bermain sekaligus belajar, maka akan lebih meningkatkan motivasi belajar siswa.

\subsection{Multimedia}

Multimedia diambil dari kata multi dan media. Multi berarti banyak dan media berarti perantara, sarana atau alat yang digunakan untuk menyampaikan informasi. Sehingga pengertian multimedia adalah gabungan beberapa elemen atau media seperti teks, gambar, audio, video dan animasi untuk menyampaikan suatu informasi yang baik dan sangat menarik yang dapat disajikan secara linier ataupun interaktif yang dapat dengan mudah diterima oleh indra penglihatan dan pendengaran manusia.

Komputer multimedia mulai mendapat perhatian pada saat digunakan untuk pelatihan atau pendidikan dari satu keadaan ke keadaan lain dengan siswa. Presentasi multimedia dapat menggunakan beberapa macam teks, chart, audio, video, animasi, simulasi atau foto. Bila macam-macam komponen tersebut digabungkan secara interaktif, maka menghasilkan suatu pembelajaran yang efektif.

\subsection{Rumus Matematika Bangun Ruang}

Bangun ruang adalah bangun matematika yang mempunyai isi ataupun volume.

Berikut ini macam-macam bangun ruang:

1. Kubus

Kubus terdapat 6 (enam) buah sisi yang berbentuk persegi dengan luas yang sama besar diantara sisinya. Terdapat 12 (dua belas) rusuk dengan panjang rusuk yang sama panjang. Semua sudut bernilai 90 derajat ataupun siku-siku.

\section{Rumus:}

Luas salah satu sisi = rusuk $x$ rusuk 
Luas Permukaan Kubus $=6 x$ rusuk $x$ rusuk

Keliling Kubus $=12 x$ rusuk

Volume Kubus = rusuk $x$ rusuk $x$ rusuk ( rusuk 3 )

2. Balok

Sifat-sifat yang menjadi cirikhas dari balok adalah: Mempunyai empat buah sisi dengan bentuk persegi panjang, ada dua buah sisi yang memiliki bentuk sama. terdapat empat buah rusuk yang memiliki ukuran sama persis.

\section{Rumus:}

Luas Permukaan Balok $=2 x\{(p x l)+$ $($ pxt $)+($ lxt $)\}$

Diagonal Ruang $=$ Akar dari $(p$ kuadrat + l kuadrat + t kuadrat)

Keliling Balok $=4 x(p+l+t)$

Volume Balok $=p x$ l x t (sama dengan

kubus, tapi semua rusuk kubus sama panjang).

3. Prisma Segitiga

Sifat-sifat yang menjadi cirikhas dari prisma adalah: Mempunyai tiga buah sisi, dua buah sisi berbentuk segitiga dan tiga buah sisi berbentuk persegi panjang. mempunyai 6 buah titik sudut, jumlah rusuknya ada Sembilan

Rumus:

Luas Prisma $=(2 . l u a s$ alas $)+$ luas selubung

Volume Prisma $=$ luas alas $\times$ tinggi

4. Limas Segitiga

Sifat-sifat yang menjadi cirikhas dari limas segitiga adalah: Memiliki alas yang berbentuk segitiga, terdapat tiga buah sisi yang bentuknya segitiga, terbentuk dari enam buah rusuk, mempunyai tiga rusuk yang sama persis ukurannya, mempunyai titik puncak atas.

\section{Rumus: \\ Rumus Luas Limas Segitiga $=$ jumlah luas keempat sisinya \\ Rumus Volume limas segitiga yaitu $V=$ $1 / 3 \times\{1 / 2 \times$ Panjang $x$ Lebar $\} \times$ Tinggi}

Sifat-sifat yang menjadi cirikhas dari limas segiempat adalah: Bentuk alasnya berupa segiempat, mempunyai empat buah sisi yang bentuknya segitiga dan ada empat buah rusuk yang ukurannya sama persis. Mempunyai titik puncak atas.

\section{Rumus:}

Volume $=1 / 3$ luas alas tinggi sisi

Luas = luas alas + jumlah luas sisi tegak

6. Kerucut

Sifat-sifat yang menjadi ciri khas kerucut adalah: Mempunyai sebuah alas yang bentuknya lingkaran, mempunyai titik puncak atas dan memiliki selimut (sisi) yang berbentuk lengkungan.

Rumus:

Volume $=1 / 3 \times \pi \times r \times r \times t$

Luas = luas alas + luas selimut

7. Tabung

Sifat-sifat yang menjadi ciri khas tabung adalah: Memiliki sisi alas dan atas yang bentuknya sama berupa lingkaran. Mempunyai sisi lengkung atau selimut yang menghubungkan sisi alas dan atas.

Rumus:

Volume = luas alas $x$ tinggi, atau luas

lingkaran $x t$

Luas = luas alas + luas tutup + luas

selimut, atau

$$
(2 x \pi x r \times r)+\pi x d x t)
$$

8. Bola

Sifat-sifat yang menjadi cirikhas dari bola adalah: Hanya memiliki satu buah sisi, tidak mempunyai titik sudut, hanya mempunyai sebuah sisi lengkung yang tertutup

\section{Rumus:}

Luas Bola $=4 x \pi x$ jari-jari $x$ jari-jari, atau

$4 x \pi x r^{2}$

Volume Bola $=4 / 3 \times \pi x$ jari-jari $x$ jarijari $x$ jari-jari

$$
\pi=3,14 \text { atau } 22 / 7
$$

Inilah tabel lengkap jumlah sisi, titik sudut, dan rusuk dari bangun ruang:

5. Limas Segiempat 
Tabel 1. Tabel bangun ruang

\begin{tabular}{llccc}
\hline No & \multicolumn{1}{c}{$\begin{array}{c}\text { Nama Bangun } \\
\text { Ruang }\end{array}$} & Sisi & $\begin{array}{c}\text { Titik } \\
\text { Sudut }\end{array}$ & Rusuk \\
\cline { 3 - 5 } & & 6 & 8 & 12 \\
\hline 1 & Kubus & 6 & 8 & 12 \\
2 & Balok & 5 & 6 & 9 \\
3 & Prisma Segitiga & 4 & 4 & 6 \\
4 & Limas Segitiga & 5 & 5 & 8 \\
5 & Limas Segiempat & 2 & 0 & 1 \\
6 & Kerucut & 3 & 0 & 2 \\
7 & Tabung & 1 & 0 & 0 \\
8 & Bola & & & \\
\hline
\end{tabular}

\section{ANALISIS DAN PERANCANGAN SISTEM}

\subsection{Analisa Sistem}

Sebelum Sistem pembelajaran untuk menghitung rumus matematika bangun ruang dibuat dan dikembangkan terlebih dahulu dilakukan tahapan analisia sistem. Analisa sistem sangat diperlukan untuk mengetahui berbagai kebutuhan pengguna dan sistem, yaitu berupa masukkan dan keluaran yang dibutuhkan. Dengan adanya analisa yang baik maka pembuatan dan pengembangan sistem akan berjalan dengan baik dan sesuai dengan yang diharapkan.

Pada sistem pembelajaran untuk menghitung rumus matematika bangun ruang ini dirancang berdasarkan materi yang ada didalam pelajaran matematika.

\subsection{Perancangan Flowchart}

Adapun flowchart dari program adalah sebagai berikut:

1. Perancangan flowchart Login Sistem

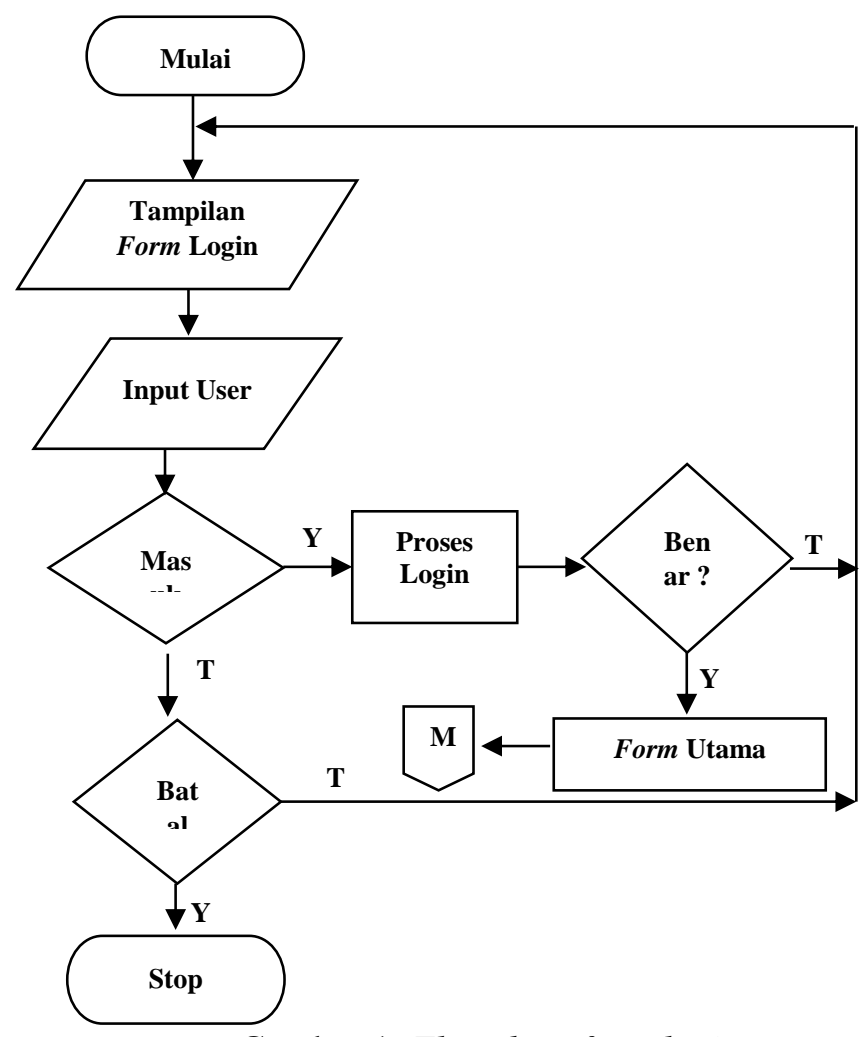

Gambar 1. Flowchart form login 
2. Perancangan Flowchart Menu Utama
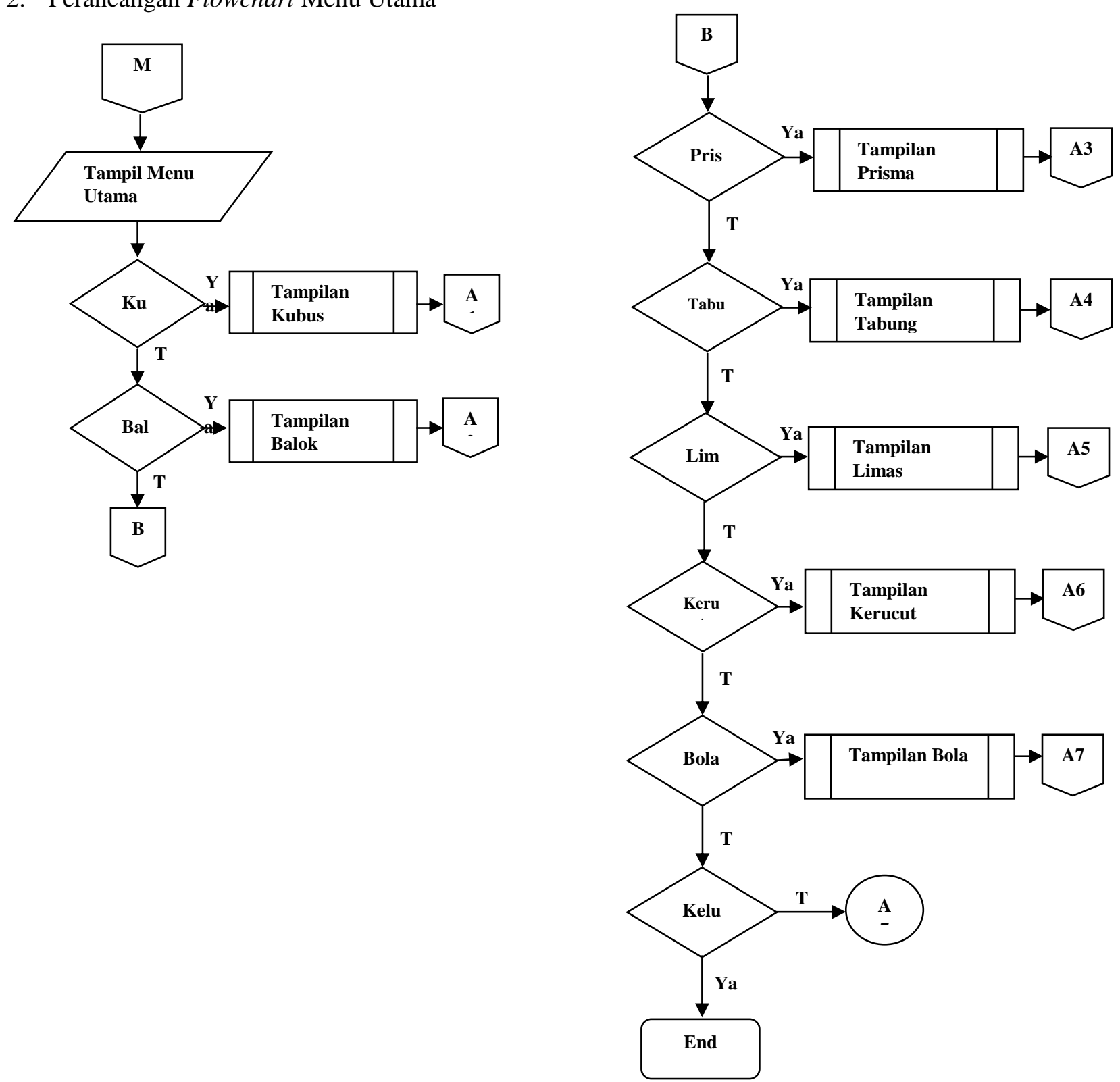

Gambar 2. Flowchart menu utama 
3. Perancangan flowchart Bangun Ruang Kubus

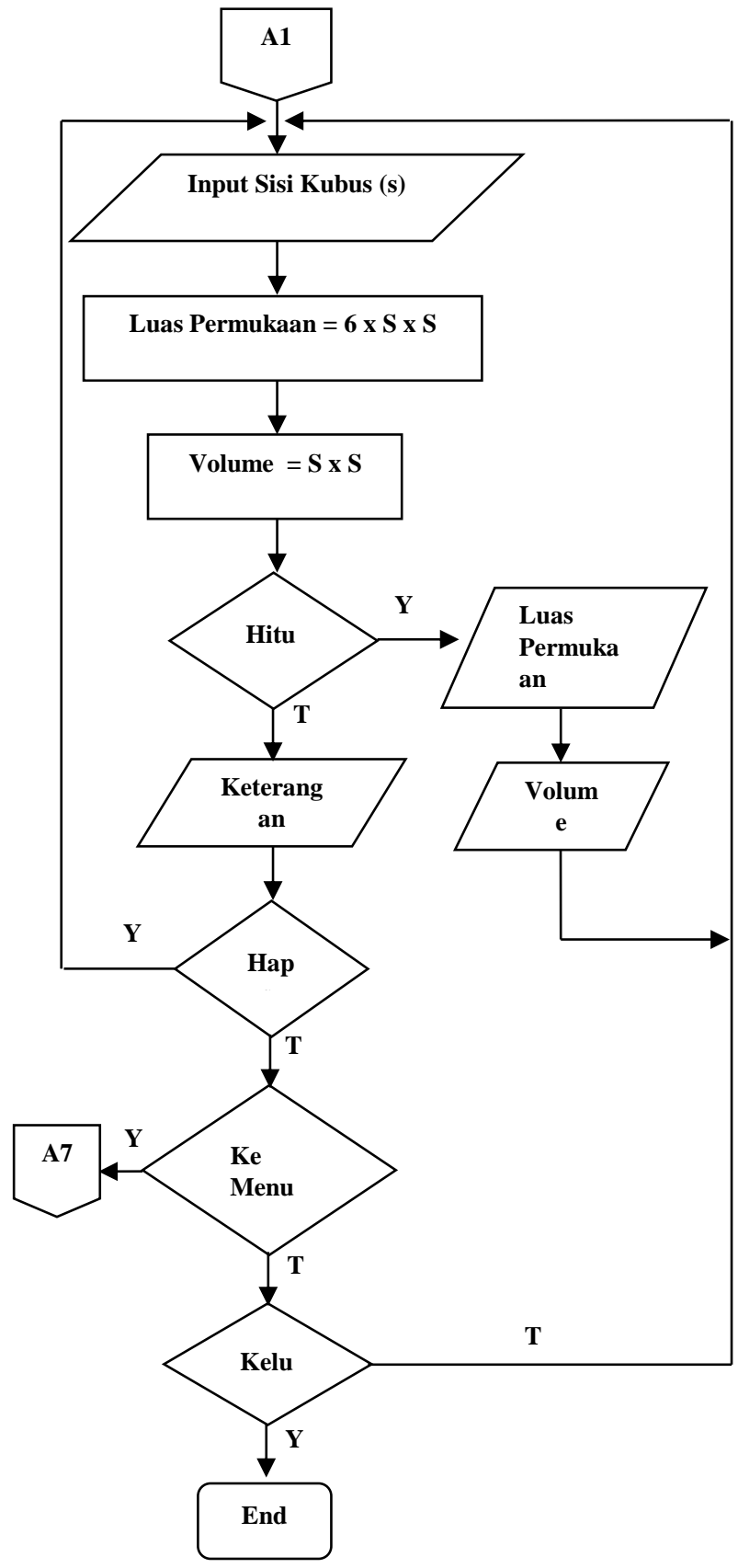

4. Perancangan flowchart Bangun Ruang Balok



Gambar 4. Flowchart menu balok

Keterangan: Flowchart bangun ruang prisma, tabung, limas, kerucut dan bola tidak ditampilkan, karena hampir sama dengan bangun ruang balok dan tergantung dengan rumus. 


\section{HASIL DAN PEMBAHASAN}

Implementasi sistem merupakan tahap yang dilakukan setelah selesai melakukan perancangan sistem. Dalam implementasi sistem ini dilakukan persiapan terhadap perangkat-perangkat sistem yang diperlukan. Karena sistem yang dirancang harus didukung oleh perangkat-perangkat yang memadai, agar sistem dapat bekerja sesuai dengan yang diinginkan.

Pada waktu melakukan implementasi dilihat apakah hasil rancangan yang menjadi sebuah program aplikasi dapat dioperasikan dan mencapai hasil yang sesuai dengan rancangan. Setelah melakukan tahapan analisis dan perancangan maka selanjutnya adalah mengimplementasikan hasil aplikasi yang dibuat.

Berikut hasil implementasi sistem pembelajaran untuk menghitung rumus matematika bangun ruang. Gambar 5 di bawah ini adalah tampilan login pada sistem pembelajaran.

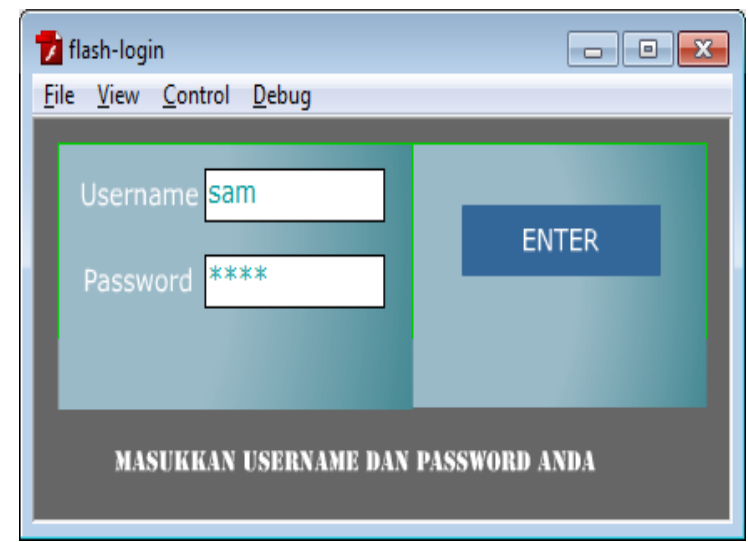

Gambar 5. Tampilan Form utama

Form Login digunakan sebagai pengaman untuk pemberian hak akses pada user yang diperkenankan untuk membuka sistem pembelajaran.

Pada Gambar 6 di bawah ini adalah Form menu utama dari sistem pembelajaran untuk menghitung rumus matematika bangun ruang.

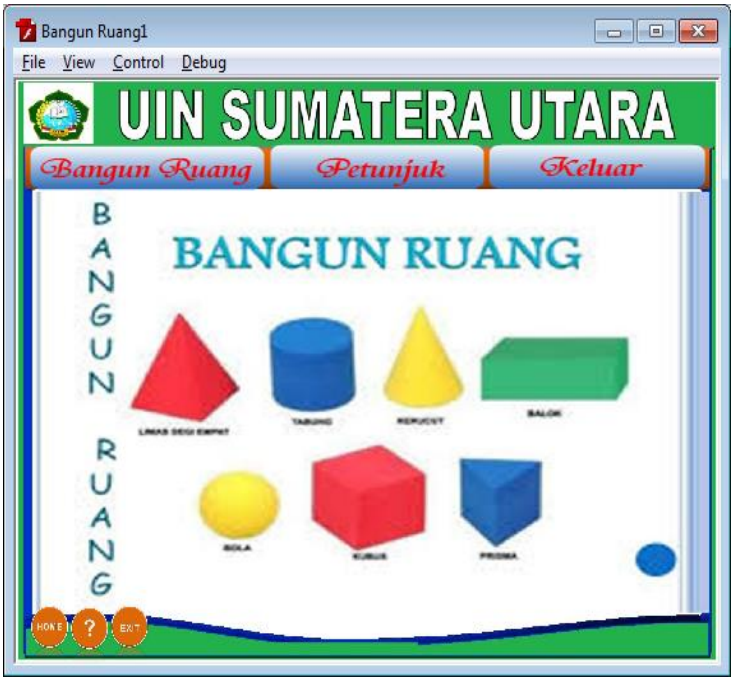

Gambar 6. Form menu utama sistem pembelajaran

Menu utama merupakan suatu tampilan yang berfungsi sebagai media panampung dari menu-menu yang lainnya seperti menu Bangun Ruang, Petunjuk dan Keluar. Disini user diajak untuk memilih salah satu pilihan bangun ruang yang tesedia dengan cara mengklik menu pilihan bangun ruang.

Pada Gambar 7 di bawah ini adalah beberapa sub menu dari menu bangun ruang dari sistem pembelajaran.

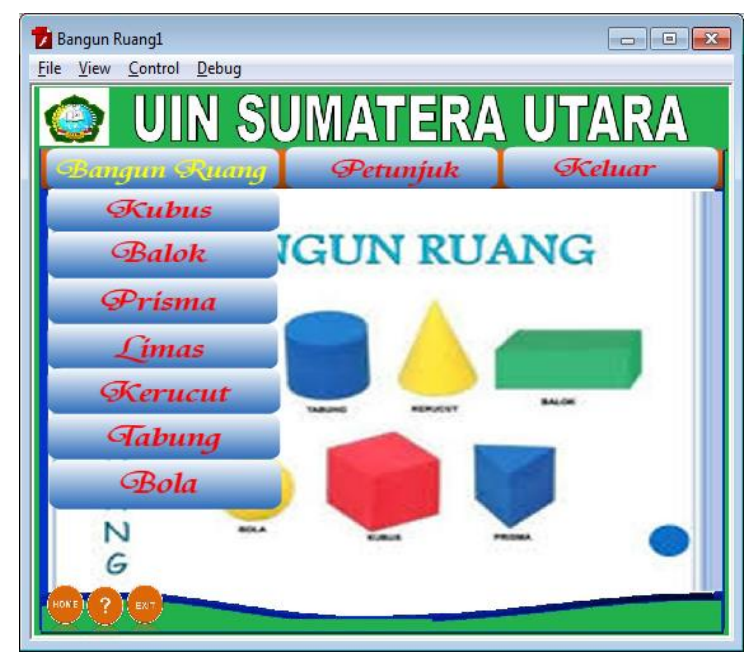

Gambar 7. Sub menu bangun ruang

Pada menu bangun ruang terdapat sub menu kubus, balok, prisma, limas, kerucut, tabung dan bola. Jika diklik sub menu kubus maka akan muncul Form perhitungan kubus seperti Gambar 8 di bawah ini: 


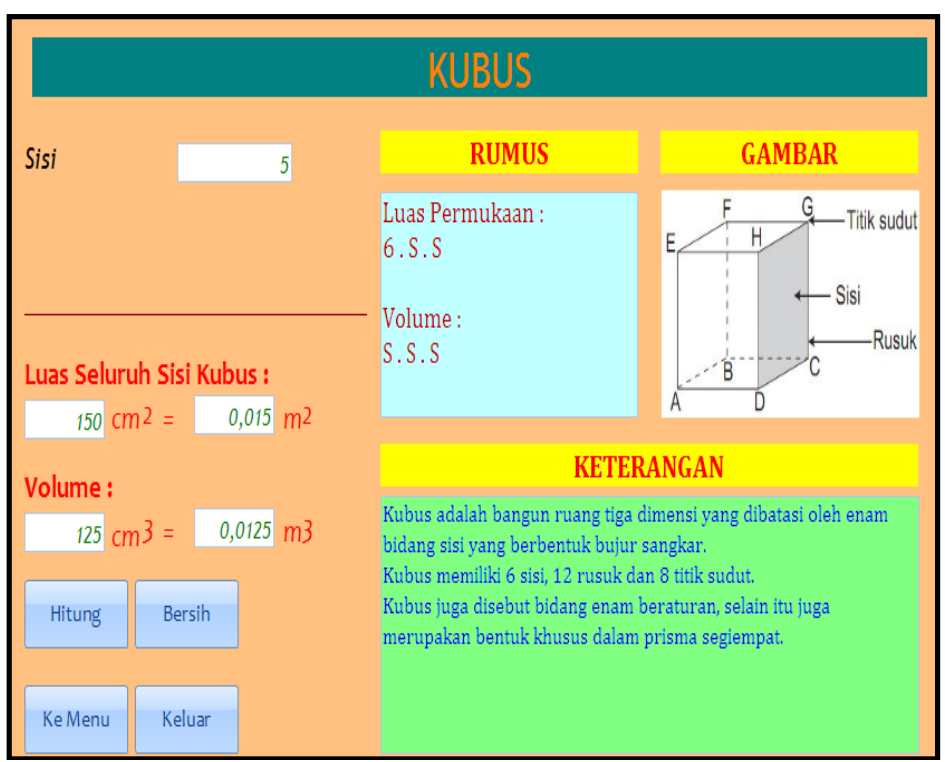

Gambar 8. Form perhitungan kubus

Kemudian jika diklik sub menu balok maka akan muncul Form perhitungan balok seperti Gambar 9 di bawah ini:

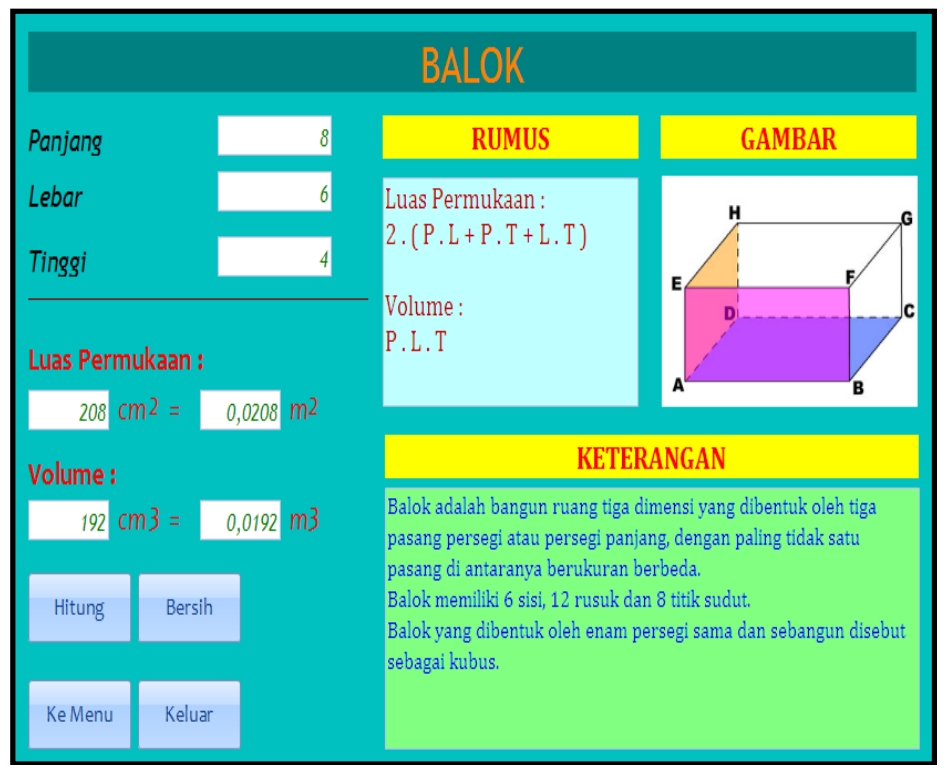

Gambar 9. Form perhitungan balok

Kemudian jika diklik sub menu prisma maka akan muncul Form perhitungan prisma seperti Gambar 10 di bawah ini: 


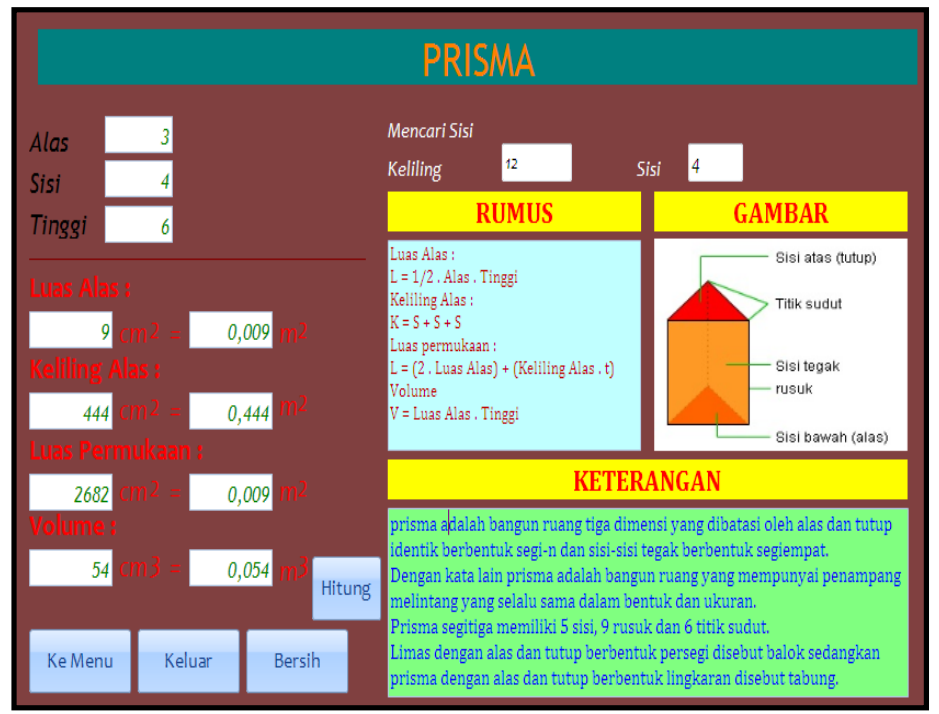

Gambar 10. Form perhitungan prisma

Kemudian jika diklik sub menu limas maka akan muncul Form perhitungan limas seperti Gambar 11 di bawah ini:

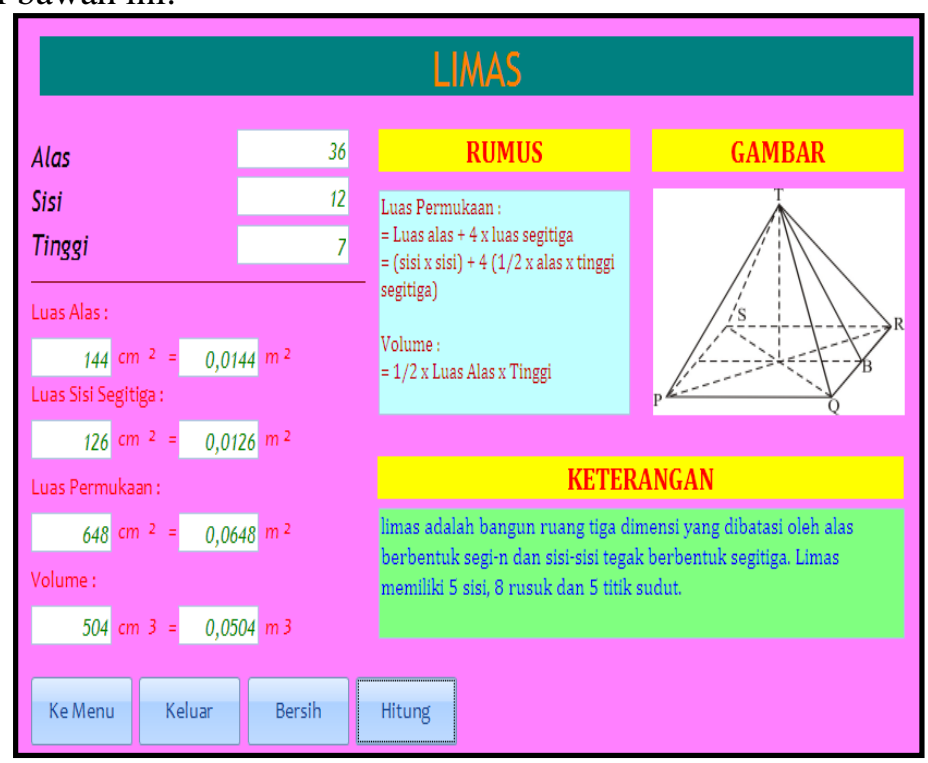

Gambar 11. Form perhitungan limas

Kemudian jika diklik sub menu kerucut maka akan muncul Form perhitungan kerucut seperti Gambar 12 di bawah ini: 


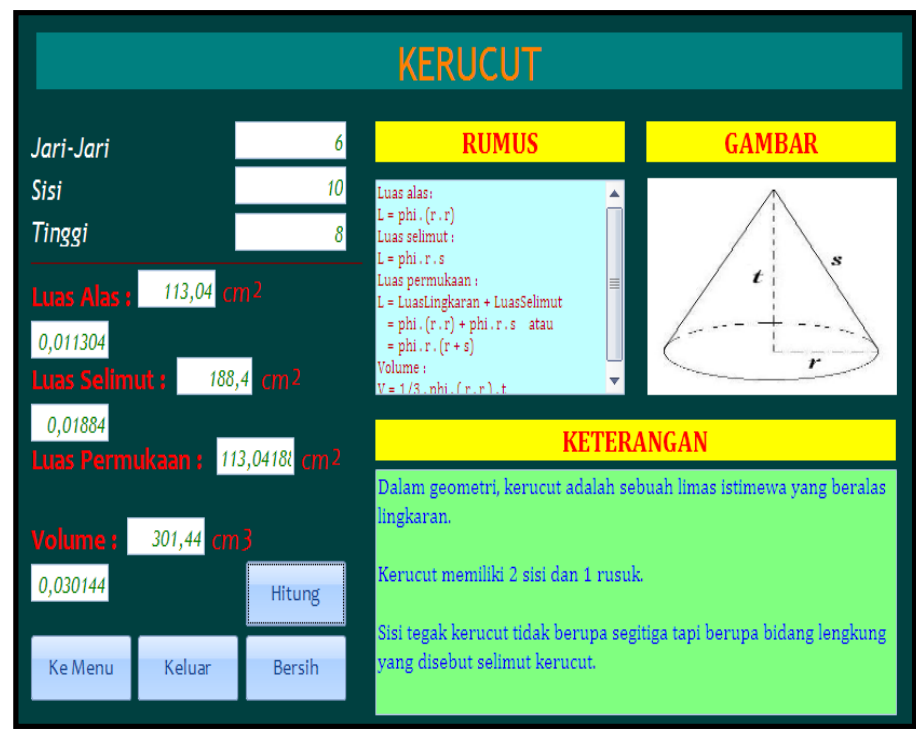

Gambar 12. Form perhitungan kerucut

Kemudian jika di-klick sub menu tabung maka akan muncul Form perhitungan tabung seperti Gambar 13 di bawah ini:

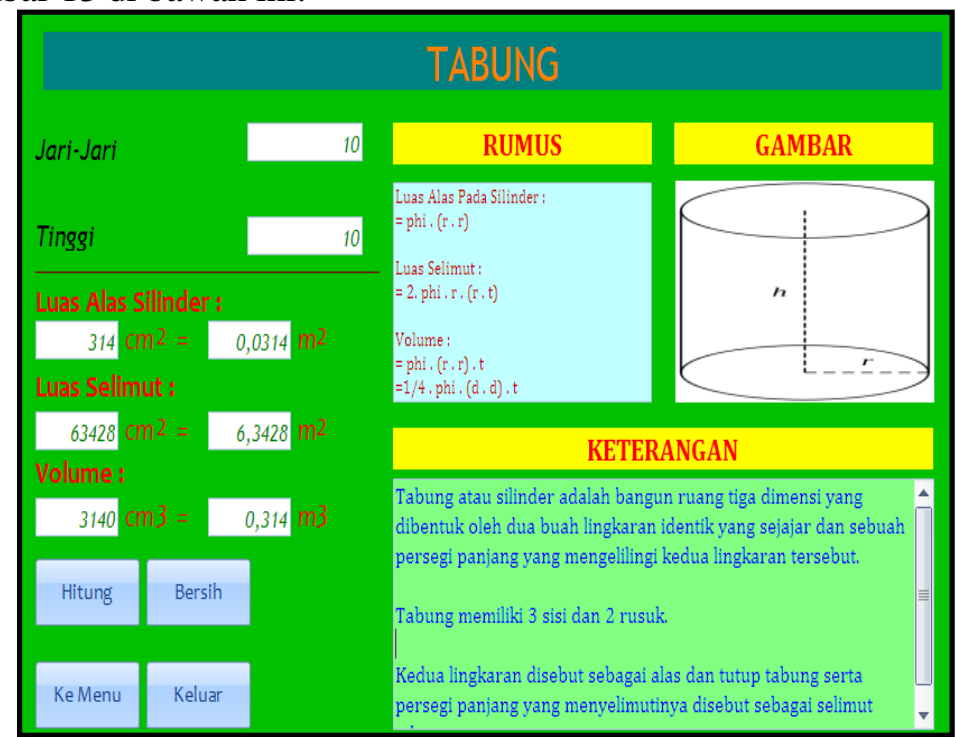

Gambar 13. Form perhitungan tabung

Kemudian jika di-klick sub menu bola maka akan muncul Form perhitungan bola seperti Gambar 14 di bawah ini: 


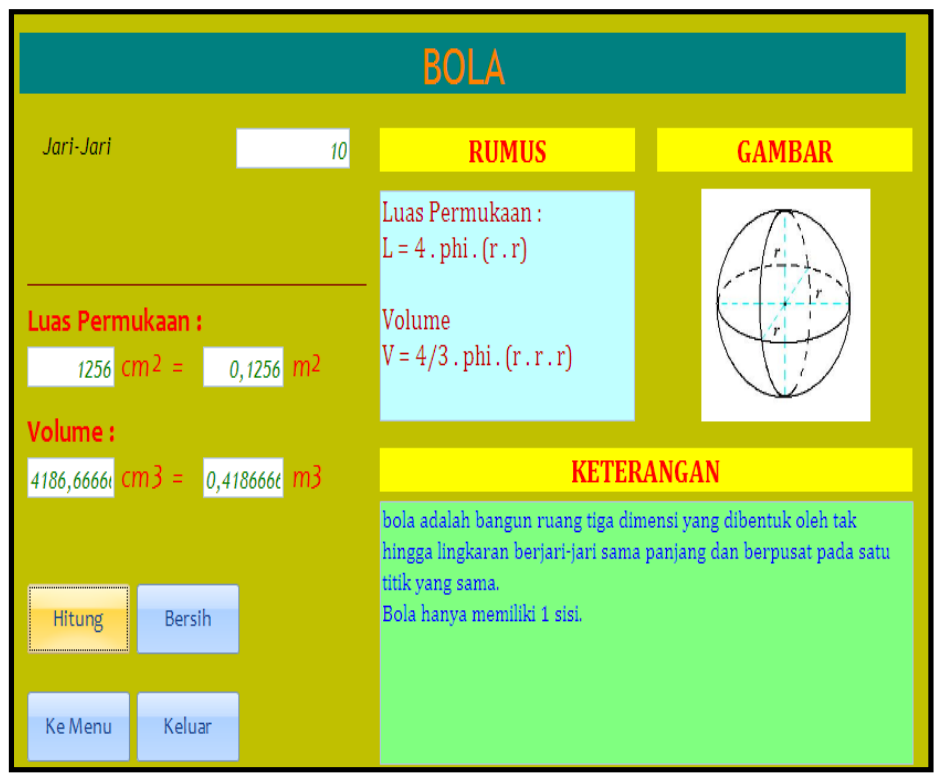

Gambar 14. Form perhitungan bola

\section{PENUTUP}

Kesimpulan dari pembuatan makalah ini antara lain sistem pembelajaran ini digunakan bagi para siswa/siswi dalam mempelajari matakuliah matematika yang didalamnya terdapat pilihan-pilihan menu yang dapat dipilih oleh user untuk menjalankan perhitungan bangun ruang. Sistem pembelajaran ini dibuat untuk meningkatkan keinginan siswa/siswi dalam belajar matakuliah matematika khususnya tentang perhitungan bangun ruang. Dalam menyusun suatu sistem perhitungan yang baik, diperlukan tahapantahapan antara lain: mempelajari sistem yang ada atau berlaku saat ini, merumuskan permasalahan yang ada, mencari alternatif penyelesaian untuk masalah yang ada, kemudian merancang suatu sistem yang dapat mengatasi masalah tersebut serta mengimplementasi sistem yang dirancang.

\section{DAFTAR PUSTAKA}

[1] Alessi, S.M., Trollip, S.R. 1991. Computer Based Instruction: Methods and Development. New Jersey: Prantice Hall.

[2] Elcom. 2011. Seri 30 Menit Menguasai Adobe Flash Cs 5, Penerbit Andi Publisher Yogyakarta.

[3] Hannafin, M. J. \& Peck, K. L. 1988. The design, development, and evaluation of instructional software. New York: Macmillan Publishing Company.

Samsudin: Aplikasi Computer...
[4] Harto, P. 1996, Media Pembelajaran Menggunakan Komputer, Yogyakarta: Andi Offset.

[5] Hastuti. 1997. Strategi Belajar Mengajar Bahasa Indonesia. Jakarta: Depdikbud.

[6] Heinich, R. dkk. 1993. Instructional Media (and the new technologies of instruction). New York: Memillan Publishong.

[7] Jogyanto, H. 2000. Pengenalan Komputer: Dasar Ilmu Komputer, Pemograman, Sistem Informasi dan Intelegensi Buatan. Andi Yogyakarta. Yogyakarta.

[8] Madcoms. 2012. Mahir Dalam 7 Hari: Adobe Flash Pro Cs5.5 Penerbit Andi Publisher Yogyakarta.

[9] Madcoms. 2011. Kupas Tuntas Adobe Flash Profesional Cs5 Penerbit Andi Publisher Yogyakarta.

[10] Mayer, Richard E. 2009. Multimedia Learning Prinsip-Prinsip dan Aplikasi. Yogyakarta: Pustaka Pelajar. Surabaya: ITS Press.

[11] Munir. 2010. Prospek Komputer Sebagai Media Pembelajaran Interaktif Dalam Sistem Pendidikan Jarak Jauh di Indonesia.

[12] Rossett, Allison, 2002. The ASTD ELearning Handbook, New York: McGraw-Hill Companies Inc, USA.

[13] Suyoto, Sunardi. 2005. Latihan Multimedia dan Aplikasinya. Jakarta: PT. Elex Media Komputindo. 
[14] Daryanto T. 2005. Sistem Multimedia dan Aplikasinya. Penerbit Graha Ilmu.

[15]http://www.allmipa.com/2015/08/penjelas an-lengkap-sifat-dan-rumus.html unduh 08 Agustus 2017

[16]http://www.slideshare.net/sucihayaty/bang un-ruang-matematika unduh 10 Agustus 2017

[17]http://eduwari.blogspot.co.id/2012/09/pem belajaran-berbantuan -komputerpbk.html unduh 27 Agustus 2017

[18]http://www.nblognlife.com/2014/01/pemb elajaran-berbantuan-komputer.html unduh 27 Agustus 2017

[19] Nasution, M.I.P. 2016. Strategi pembelajaran efektif berbasis mobile learning pada sekolah dasar, IQRA': Jurnal Perpustakaan dan Informasi, vol 10, No 1 (2016) 